\title{
PREVENTION OF RETAINED FETAL MEMBRANE BY USING VARIOUS DRUGS IMMEDIATELY AFTER PARTURITION IN COWS
}

\author{
M. A. A. Azad ${ }^{1}$, M. M. Rahman ${ }^{1 *}$, B. Sinha ${ }^{1}$, M. M. Shamsuddin ${ }^{1}$ and F. Y. Bari ${ }^{1}$ \\ ${ }^{1}$ Department of Surgery and Obstetrics, Faculty of Veterinary Science, Bangladesh Agricultural University, \\ Mymensingh-2202, Bangladesh
}

\begin{abstract}
The aim of the study was to investigate for the effect of different drugs immediately after parturition on the reduction of retention of placenta in selected cows. One hundred pregnant cows from members of Community Based Dairy Veterinary Foundation, Shikalbaha, Potiya, Chittagong were included in this study belonged to two breeds viz, cross bred and local, aged 3-8 years, calved 1-5 times with BCS 2-3.5. The cows were divided into five groups; group L ( $\mathrm{n}=20)$ treated with oxytocin 50 iu/intramuscular, group IL ( $n=20)$ treated with calcium $400 \mathrm{ml} /$ intravenous, group III: $(\mathrm{n}=20)$ treated with methyl ergometrine maleate $20 \mathrm{mg} /$ intramuscular, group IV: $(\mathrm{n}=20)$ treated with oxytocin $50 \mathrm{iu} /$ intramuscular plus calcium $400 \mathrm{ml} /$ intravenous and group V: $(n=20)$ served as non-treated control. The incidence of retained fetal membrane was $35 \%$ in control group, while that of pooled treatment group had $15 \%$. This reduction was significant $(\mathrm{P}<0.05)$. In the present study, there was no significant difference among the different treatment groups on the prevention of retention $(\mathrm{P}>0.05)$. The incidence of retained fetal membrane was affected by the age and breed of cows $(\mathrm{P}<0.05)$. However, this effect was override by treatment and injection of drugs immediately after parturition decreases the incidence of retention of placenta in cows.
\end{abstract}

Keywords: Cows, drugs, parturition, retained fetal membrane

\section{INTRODUCTION}

Dairy farmers target a maximum period of 60 to 90 days open and to get one calf per cow per year. Retention of placenta prolongs days open which results in decreased milk production, fertility, market value of the animals (Ahmed et al., 1999; Semacan and Sevinc, 2005) and increase calving interval, culling rate and treatment and labour cost (Kelton et al., 1998; Ahmed et al., 2004). Affected animal health deteriorates. There are many factors influencing the incidence of retained fetal membranes like abortion, dystocia, multiple birth, poor BCS, age, nutritional deficiencies, hormonal imbalance (Grunert, 1986; Alam and Dobson, 1987) season of the year and premature birth. Inadequacy of oxytocin and calcium are important agents associated with retention of placenta.

The incidence of retention of afterbirth is much more common in dairy breeds than in beef breeds and much common in crossbred than their pure breed counterparts (Roberts, 1986). The incidence of retained fetal membrane appears to be varying from area to area and from year to year (Grunert, 1980; Paisley et al., 1986; Youngquist and Threlfall, 2007). A higher incidence rate was observed in younger cows than older one. Aged cows showed a higher incidence $(37 \%)$ of retained fetal membrane than 4, 5, 6, 7 years old. The number of calving was negatively correlated with the incidence of retained fetal membrane. A higher incidence $(44.7 \%)$ affected the heifers after their calving while it was 10-13\% after second and third calving, 10-21\% after fourth and fifth ones (Majeed et al., 2009). Nutritional status (Body score) might also be associated with retention of placenta immediately after parturition since it affects the endocrine status chronically.

The incidence of retention of placenta in cattle ranged between 5.2 and 23.5\% (Roberts, 1986; Majeed et al., 1989). Its incidence can be as high as $12 \%$ even in normal delivery (Dewan and Rahman, 1987). Shamsuddin et al. (1988) recorded about $63 \%$ of the retained placenta out of 750 calving in Savar Dairy Farm. The highest incidence was recorded in March and lowest in September. However, from clinical and economical point of view, prevention rather than therapy of this disorder is important with regard to the reproductive and general heath status of the herds.

It is important to reduce the incidence of retained placenta. Therefore the present study was undertaken to adopt precise treatment protocol for the prevention of retention of placenta and identify the effective treatment

*Corresponding e-mail address: mrahmanvet1978@gmail.com Copyright (c) 2016 Bangladesh Society for Veterinary Medicine 


\section{A. A. Azad and others}

(oxytocin, calcium, methyl ergometrine maleate and combination of oxytocin plus calcium) for the prevention of retention of placenta. This study also evaluate the effects of age, breed, parity and BCS of dairy cows on prevention of retention placenta following treatment.

\section{MATERIALS AND METHODS}

One hundred pregnant cows were given preventive treatments and the incidence of retained placenta were recorded, if the fetal membranes were not expelled within 12 hours after birth. The cows were divided into 5 groups and individual group were treated with any of the five treatment regimens.

\section{Study area}

The present study was carried out as a part in Potiya Thana under the Chittagong District during the period from $15^{\text {th }}$ March to $20^{\text {th }}$ April, 2010. The area covered $5 \mathrm{~km}$ radius under the operation of Community Based Dairy Veterinary Foundation, Potiya, Chittagong.

\section{Selection and grouping of cows}

The cows were selected mainly for milk production and managed under traditional system. The cows belonged to 50 different dairy farms and each farm had 5-10 dairy cows. A total of 120 advanced pregnant cows were selected and 100 calving were screened out. The screened cows were divided into 5 groups having 20 cows per group. The cows were divided into 4 groups according to age, breed, parity and body condition score (BCS) regardless of treatment type.

\section{Brief description of the experimental design}

The present study was favorably parted into two phases; phase I included an epidemiological data collection to identify the risk factors associated with the prevalence of retained placenta in dairy cows. In phase II, efforts were made to evaluate the efficacy of various drugs and their combinations given immediately after parturition.

\section{Clinical examination of the animals \\ General health status}

The nutritional status (body condition score) of the animals were categorized into good health, borderline health, poor health and cachectic health using the lumber vertebral process as landmark condition scores. Ranged from 0 (very thin) to 5 (very fat) (Ahmed et al., 1999). I used 1-5 scale.

\section{Data collection}

A full case history and owner complain of each animal was recorded. A questionnaire was used to record information regarding age at birth, breed, parity, nutritional status, date of parturition, history of abnormal deliveries, twin birth, cesarean section, fetotomy, premature birth, abortion and milk fever. Most of the information were collected from the individual animal card, routine clinical case register and milk register maintained at the dairy farm and by interviewing the owner of the animals.

The age of the animals were determined either by enquiring date of birth or observing the eruption and wearing of incisor teeth. The fetal membranes were defined as retained when it had not been expelled within 12 hours after calving. The general trends of the farmers toward handling the individual retention of afterbirth cases were recorded.

\section{Treatment after parturition}

The cows were divided into 5 groups with 20 cows per group. Each group was treated with different drugs immediately after parturition for prevention of retention of placenta.

The following treatment schedule was designed to treat the cows.

Group I: Oxytocin (Oxin ${ }^{\circledR,}$ Techno Drugs Limited, Dhaka) at the dose rate of 50 iu/cow i.m.

Group II: Calcium (Cal-D-Mag ${ }^{\circledR,}$ Renata Animal Health Limited, Dhaka) at the dose rate of $400 \mathrm{ml} / \mathrm{cow}$ i.v. Group III: Methyl ergometrine maleate (Metharspan ${ }^{\circledR}$, Opsonin, Dhaka) at the dose rate of $20 \mathrm{mg} / \mathrm{cow}$ i.m. Group IV: Oxytocin plus calcium at the dose rate of 50 iu/cow i.m. plus $400 \mathrm{ml} /$ cow Group V: Control group without any treatment. 


\section{Statistical analysis}

Percentages of cows with placenta retained more than 12 hours with or without treatment were calculated. The difference between treatment and control group, between each treatment group, and effects of other variables on retention of placenta were determined by Chi-Squired test.

Incidence of retained placenta $=\frac{\text { Numberof retained placenta }}{\text { Totalnumber of parturition }} \times 100$

\section{RESULTS AND DISCUSSION}

The present study was conducted to observe the effect of various drugs injecting immediately after parturition on the incidence of retention of placenta. Prior to this study 100 calving were divided into two groups in which one was treated group and another was control group.

A total of 100 calving were observed for the prevention of retention of placenta by injecting various drugs immediately after parturition. The percentages of retained placenta in both pooled treatment and control groups are presented in Table 1. The overall rates of retention were 15 and $35 \%$ in treatment and control group, respectively. The significantly $(\mathrm{P}<.05)$ higher percentage of prevention was observed in treatment group compared to control group.

Table 1. Comparison of retained placenta between treatment and control group

\begin{tabular}{ll}
\hline Groups & No. $(\%)$ of retained \\
\hline Treatment group $(\mathrm{n}=80)$ & $12(15)^{\mathrm{b}}$ \\
Control group $(\mathrm{n}=20)$ & $7(35)^{\mathrm{a}}$ \\
\hline
\end{tabular}

a,b The values with superscript within the same column differed significantly from each other $(\mathrm{P}<.05)$

In the present study the overall rates of retention of placenta were $15 \%(12 / 80)$ and $35 \%(7 / 20)$ for the treatment and control group respectively. Our findings indicate that $35 \%$ retention of placenta in control group that is consistent with the findings of Dewan and Rahman (1987), but not similar with the findings of other researcher viz, Shamsudddin et al. (1988) and, Kucharski and Zdunczyk (1984) who reported 42.3\% and 52\%, retention of placenta, respectively. This discrepancy could be due to many causes for retention of placenta including the number of animals observed and breed of cows.

Retention was more in control group, which were prevented by treatment with various drugs injecting immediately after parturition. Therefore, the present study indicates that retention of placenta in dairy cows can be reduced 2.3 times in treatment group compared to control group by injecting various drugs immediately after parturition.

The occurrence of retained placenta were 10, 15, 30 and 5\% in groups I, II, III and IV, respectively (Table 2). The lowest percentages of retained placenta i.e. the highest percentage of prevention were observed in oxytocin plus calcium treated group. The difference was not significant $(\mathrm{P}>0.05)$ among groups.

Table 2. Comparison among treatments on the occurrence retained placenta

\begin{tabular}{lll}
\hline Group & Treatment & No. $(\%)$ of retained \\
\hline I & Oxytocin $(\mathrm{n}=20)$ & $2(10)$ \\
II & Calcium $(\mathrm{n}=20)$ & $3(15)$ \\
III & Methyl ergometrine maleate $(\mathrm{n}=20)$ & $6(30)$ \\
IV & Oxytocin + Calcium $(\mathrm{n}=20)$ & $1(5)$ \\
\hline
\end{tabular}

Hormone oxytocin and calcium has the principal effect in separating fetal membranes from maternal caruncles by virtue of their effects on smooth muscle contraction and increasing the tonacity. Since ergometrine group of drugs got the similar property like hormone oxytocin, the present study included that drug to be used for prevention of retention of placenta.

To find out the most effective drug for the prevention of retention of placenta in the present study the parturient cows were injected with oxytocin, calcium, methyl ergometrine maleate and oxytocin plus calcium 


\section{A. A. Azad and others}

immediately after delivery. The incidence of retention was $10,15,30$ and $5 \%$, respectively. The highest rate of prevention of retention of placenta was found in oxytocin plus calcium group and lowest rate was methyl ergometrine maleate group. The best result obtained after administration of oxytocin plus calcium in this study. Arthur et al. (1989) reported that oxytocin injection to cows immediately after calving reduced the rate of retention from 10 to $1 \%$ as it has got ecbolic properties to provide myometrial contractility or to correct uterine atony which required for the successful expulsion after birth. Our findings differs from the statement of Roberts (1986) that administration of $3 \mathrm{mg}$ of ergometrine or similar drug developed from the ergot, may be more beneficial than oxytocin in cases of atonic myometrium because of its prolonged oxytocin effect. Our results differs from that statement and it could be due to difference in time of injection after delivery as the number of oxytocin receptors reduce about 12-20 hours after delivery. In the present study the differences in drug among treatment group were not significantly $(\mathrm{P}>0.05)$ different, although oxytocin and calcium resulted in highest prevention. The less number of cows investigated in the present study may be the limitation.

The percentages of retained placenta in cross breed and local cows of both treatment and control group are presented in Table 3. The overall rates of retention in cross and local breed were 14.7 and $16.7 \%$ for treatment and 37.5 and $25.0 \%$ for control group, respectively. There was no significant difference between two breeds within both treatment and control group. However, significant $(\mathrm{P}<0.05)$ difference was existed between treatment and control group within each breed type. The highest percentage of prevention was observed in treatment group cross and local breed.

Table 3. Breed effect on retained placenta between treatment and control group

\begin{tabular}{lll}
\hline Factors & Breed & No. $(\%)$ of retained \\
\hline \multirow{2}{*}{ Treatment } & Cross $(\mathrm{n}=68)$ & $10(14.7)$ \\
\multirow{2}{*}{ Control } & Local $(\mathrm{n}=12)$ & $2(16.7)$ \\
& Cross $(\mathrm{n}=16)$ & $6(37.5)$ \\
& Local $(\mathrm{n}=4)$ & $1(25)$ \\
\hline
\end{tabular}

Under the consideration of breed variation, the rates of retention in cross and local breed were $14.7,16.7 \%$ and $37.5,25.0 \%$ for the treatment and control group, respectively. So retention of placenta can be reduced to 2.5 times in cross breed and 1.7 times in local breed in treatment group compared to control group by injecting various drugs immediately after parturition. Existence of breed effects on retention of placenta studied by other authors. For examples, Dyranduhl et al. (1977) found a higher incidence of the retention of after birth in Swedish Red and White than in Swedish Friesian. Saini et al. (1988) recorded a higher retention of afterbirth among Temperate X Zebu. In general, the incidence of retention of afterbirth is much more common in dairy than beef breeds and much common in crossbred than their pure breed counterparts (Roberts, 1986). In this study the highest incidence was found in cross breed as compared with local breed in control group. But in treatment group such effects were overrides by treatment effect. No such breed study involving the treatment and control was observed in published literature, if any.

The percentages of retained placenta in different age groups are presented in Table 4 . The overall rates of retention in 3-5 years and > 5 years age groups were 16.3 and $12.9 \%$ for treatment and 33.3 and $37.5 \%$ for control group, respectively. There was no significant difference between two age groups within both treatment and control group. There was significant $(\mathrm{P}<0.05)$ difference between treatment and control group within 3-5 years age only. However, higher percentages of prevention was observed in treatment group than that in control group.

Table 4. Age effect on retained placenta between treatment and control group

\begin{tabular}{lll}
\hline Factors & Age & No. $(\%)$ of retained \\
\hline Treatment & 3-5 years $(\mathrm{n}=49)$ & $8(16.3)$ \\
& $>5$ years $(\mathrm{n}=31)$ & $4(12.9)$ \\
Control & 3-5 years $(\mathrm{n}=12)$ & $4(33.3)$ \\
& $>5$ years $(\mathrm{n}=8)$ & $3(37.5)$ \\
\hline
\end{tabular}


The risk of high incidence of retention of afterbirth with the advancing ages and parities could be related to increasing number of calving, calving related difficulties, uterine infection and residual infection of the previous parturition. Moreover, risks of gradual declining of uterine contractility, reduced motor function that reduces the responsive sensitivity of the myometrium to various drugs might also be associated with the aged cows with higher parities (Slama et al., 1993). The incidence among aged cows and higher parity groups might be attributed to the peripartum metabolic disorders, allergic or other factors which lead to the premature calving (Correa et al., 1990; Mohanty et al., 1994). The present results are consistent with the statement that there is an effect of age on the incidence of retention of placenta in control group as the incidence was higher in $>5$ years old cows compared to 3-5 years old. However, no such effect was observed in treatment group. The overall rates of retention in 3-5 years and >5 years age groups were 16.3 and $12.9 \%$ and, 33.3 and $37.5 \%$ for treatment and control group, respectively. So retention of placenta can be reduce to 2.0 times in 35 years age and about 3 times in $>5$ years age group in treatment group compared to control group by injecting various drugs immediately after parturition.

The percentages of retained placenta in different parity group are presented in Table 5. The overall rates of retention in $1^{\text {st }}-2^{\text {nd }}$ and $3^{\text {rd }}-5^{\text {th }}$ parity were $15.0,33.3$ and $37.5 \%$ for treatment and control group, respectively. There was no significant $(\mathrm{P}>0.05)$ difference between two parity groups within both treatment and control group. Similar results were observed between treatment and control group within each parity type. However, more prevention was observed in treatment group within each parity type than that in control group.

Table 5. Parity effect on retained placenta between treatment and control group

\begin{tabular}{lll}
\hline Factors & Parity & No. $(\%)$ of Retained \\
\hline Treatment & $1^{\text {st }}-2^{\text {nd }}(n=60)$ & $9(15.0)$ \\
& $3^{\text {rd }}-5^{\text {th }}(n=20)$ & $3(15.0)$ \\
Control & $1^{\text {st }}-2^{\text {nd }}(n=12)$ & $4(33.3)$ \\
& $3^{\text {rd }}-5^{\text {th }}(n=8)$ & $3(37.5)$ \\
\hline
\end{tabular}

However, there was no significant effect of parity in control group. The incidence of retention in $1^{\text {st }}-2^{\text {nd }}$ and $3^{\text {rd }}-5^{\text {th }}$ parity groups were 15.0 and 33.3 and $37.5 \%$ for treatment and control group, respectively. So retention of placenta can be reduced 2.0 times in $1^{\text {st }}-2^{\text {nd }}$ group and 2.5 times in $3^{\text {rd }}-5^{\text {th }}$ group in treatment group compared with control group by injecting various drugs immediately after parturition However there was no significant $(\mathrm{P}>0.05)$ difference between treatment and control group within each parity type.

The percentages of retained placenta in different BCS group are presented in Table 6. The overall rates of retention in 2-3 and >3 BCS groups were 13.0 and $27.3 \%$ and, 29.4 and $66.7 \%$ for treatment and control group, respectively. There was no significant difference between two BCS group within both treatment and control group. The highest percentage of prevention was observed in treatment group compared to control group within each BCS type. However the difference was not significant.

Table 6. Effects of body condition score on retained placenta between treatment and control group

\begin{tabular}{lll}
\hline Factors & BCS & No. $(\%)$ of Retained \\
\hline Treatment & $2-3(\mathrm{n}=69)$ & $9(13.0)$ \\
& $>3(\mathrm{n}=11)$ & $3(27.3)$ \\
Control & $2-3(\mathrm{n}=17)$ & $5(29.4)$ \\
& $>3(\mathrm{n}=3)$ & $2(66.7)$ \\
\hline
\end{tabular}

The overall rates of retention in 2-3 and >3 BCS groups were 13.0 and $27.3 \%$ and, 29.4 and $66.7 \%$ for treatment and control group, respectively. The highest percentage of prevention was observed in $>3$ - BCS group in treatment group compared to control group. So retention of placenta can be reduced 2.3 times in 2-3 BCS and 2.5 times in $>3 \mathrm{BCS}$ in treatment group compared to control group. However there was no significant $(\mathrm{P}>0.05)$ difference between treatment and control group within each BCS type. The lowest and highest BCS score in the cows selected in the present study was 2.0 and 3.5. This score may not be so stress factor in causing higher percentages of retention of placenta. 


\section{A. A. Azad and others}

It may be concluded that preventive treatment reduces the incidence of retained placenta in cows and Oxytocin plus calcium was more effective treatment than other preparation (Oxytocin, Cancium, methyl ergometrine maleate). The effect of treatment influenced by breed, age, parity and body condition score of cows.

\section{REFERENCES}

1. Ahmed WM, El-Ekhnawy KI, Desouky HM, Zaabal MM and Ahmed YF (1999). Investigations on retained fetal membranes in Friesian cows in Egypt. Egyptian Journal of Comparative Pathology and Clinical Pathology 12: $160-177$.

2. Ahmed WM, El-Ekhnawy KI, El-Nattat WS, Desouky HM, Abd El-Razik KA, and El-Khadrawy HH (2004). Investigations on calving associated problems in a Friesian herd in Egypt with special reference to some prophylactic trials. Egyptian Journal of Basic and Applied Physiology 3: 65-87.

3. Alam MGS and Dobson H (1987). Postpartum release of Prostaglandins F2 alpha (PGF2 alpha) and the effect of oestradiol benzoate on the concentration of PGF2 alpha metabolite in postpartum and normal cyclic cows. Bangladesh Veterinary Journal 20: 73-81.

4. Arthur GH, Noakes DE and Pearson H (1989). Retention of fetal membrane. In: Veterinary Reproduction and Obstetrics, 5th ed. Bailliere Tindall, London. pp. 241-252.

5. Correa MT, Curtis CR, Erb HN, Scarlett JM and Smith RD (1990). An ecological analysis of risk factors for post partum disorders of Holstein-Friesian cows from thirty two New York farm. Journal of Dairy Science 73: 15151524.

6. Dewan ML and Rahman MM (1987). Studies on retention of placenta in Savar Dairy Cows. Bangladesh Veterinary Journal 21: 50-53.

7. Dyranduhl L, Mattson J and Peherson B (1977). Retained placenta in cattle incidence, clinical data and effects on fertility. Journal of the American Veterinary Medical Association 24: 529-541.

8. Grunert E (1980). Etiology of retained bovine placenta in: Morrow DA, Current Therapy in Theriogenology. Ed. W. B. Saunders Co., Philadelphia, pp. 180-189.

9. Grunert E (1986). Etiology and pathogenesis of bovine retained placenta. In: Current Therapy in Theriogenology. Edt. Morrow DA. 2nd ed. WB Saunders Co. Philadelphia, London, Toronto, Mexico city. pp. 237-242.

10. Kelton DF, Lissemore KD and Martin RE (1998). Recommendations for recording and calculating the incidence of selected clinical diseases of dairy cattle. Journal of Dairy Science 81: 2502-2509.

11. Kucharski J and Zdunchzyk S (1984). Frequency of puerperal disorders in dairy cows. Zeszyty Naukowe Akandemii Rolniczo-technicznejw Olszlunie, Welrynaria. 15: 149-154.

12. Majeed AF, Aboud QM, Hassan MS and Muhammad AY (2009). Retained fetal membranes in Friesian-Holstein cows and effect of some treatment methods. Iraqi Journal of Veterinary Sciences 23: 5-8.

13. Majeed AF, Taha MB and Qassim MY (1989). Retained placenta in local breed cattle. Mesopotamia Journal of Agriculture 21: 97-104.

14. Mohanty KC, Mohanty BN, Ray SKH and Mohanty DN (1994). Levels of glucose, calcium and alkaline phosphatase in blood with relation to retention of placenta in bovine. Indian Journal of Animal Reproduction 15: 21-23.

15. Paisley LG, Michelson WD and Anderson PB (1986). Mechanisms and therapy for retained fetal membranes and uterine infections of cows. Theriogenology 25: 353-381.

16. Roberts SJ (1986). Retention of placenta. In: Veterinary Obstetrics and Genital Diseases (Theriogenology), Woodstock, Vermont, USA. pp. 373-388.

17. Saini MS, Khanna AS and Chopra SC (1988). Incidence of retention of placenta, its treatment and subsequent fertility in crossbred (Temperate X Zebu) cattle. Indian Journal of Animal Production Management 4: 61-65.

18. Semacan A and Sevinc M (2005). Liver function in cows with retained placenta. Turkish Journal of Veterinary and Animal Sciences 29: 775-778.

19. Shamsuddin M, Alam MGS and Ahmed JU (1988). Reproductive disorders of crossbred caws. Bangladesh Veterinary Journal 22: 21-28.

20. Slama H, Vaillancourt D and Coff AK (1993). Leukotriene B4 in cows with normal calving and in cows with retained fetal membranes and/or uterine sub involution. Canadian Journal Veterinary Research 57: 293-299.

21. Youngquist RS and Threlfall WR (2007). Current Therapy in large Animal Theriogenology, 2nd ed., Saunders, ans imprint of Elsevier Inc., U.S.A. 